International Journal of Pharmacognosy and Life Science 2020; 1(2): 14-17

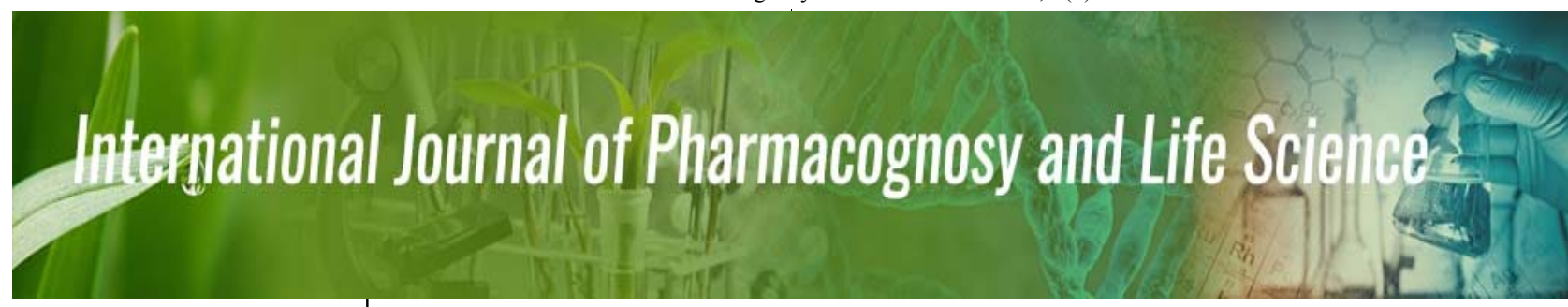

E-ISSN: 2707-2835 P-ISSN: 2707-2827 IJPLS 2020; 1(2): 14-17 Received: 13-05-2020 Accepted: 20-06-2020

Hamida AL barasi M.B.Ch.B, MSc Pharmacology and lecturer assistant at Department of Pharmacology, faculty of medicine, Benghazi University, Benghazi, Libya

Samia Elzwi

M.B.Ch.B, MSc

Pharmacology, and lecturer at Department of Pharmacology, faculty of medicine, Benghazi, Benghazi, Libya
Corresponding Author: Hamida AL barasi M.B.Ch.B, MSc Pharmacology and lecturer assistant at Department of Pharmacology, faculty of medicine, Benghazi University, Benghazi, Libya

\section{Effect of cinnamon extract on blood glucose in mice}

\author{
Hamida AL barasi and Samia Elzwi
}

DOI: https://doi.org/10.33545/27072827.2020.v1.i2a.12

\begin{abstract}
Cinnamon is a small evergreen tree 10-15 meters tall, belongs to the family Lauracae. The leaves are ovate-oblong in shape, 7-18 Cm long, the flowers which are arranged in panicles, have greenish color and distinct odor. The fruit is a purple one centiberry containing a single seed. Cinnamon are widely used as spice and flavoring agent and can be clinically used in treatment of certain diseases such as type 2 diabetes mellitus. Cinnamon extract has blood glucose lowering effect in patients with type 2 diabetes. This study tested the effect of cinnamon extract on D- glucose induced hyperglycemias which showed significant reduction in plasma glucose level. Chronic hyperglycemia model induced by a single intraperitoneal injection of streptozotocin, the extract showed marked decrease in blood glucose level.
\end{abstract}

Keywords: cinnamon extract; diabetes mellitus; d- glucose; experimental animals; and streptozotocin

\section{Introduction}

Diabetes mellitus is disease characterized by hyperglycemia it is associated with relative or absolute impairment in insulin secretion, along with varying degree of resistance to the action of insulin.

The American Diabetes Association (ADA) issued diagnostic criteria for diabetes mellitus in 1997 with follow up in2003. The diagnostic criteria are based on one of three following abnormalities: fasting plasma glucose, random elevated glucose with symptoms, or abnormal oral glucose tolerance test as shown in table $1^{[1]}$. the 2003 criteria lowered the fasting plasma glucose level used to define impaired fasting glucose (IFG) from the 1997 criteria but maintained the same definitions for diabetes and impaired glucose tolerance (IGT) as measured by an oral glucose tolerance test. Patients with IFG and / or IGT are now referred to as having pre-diabetes indicating the relatively high risk for development of diabetes in these.

There are two types of diabetes type 1 is characterized by destruction of the pancreatic B cells leading to absolute insulin deficiency. This is usually due to autoimmune destruction of B cells (Type 1A). Pancreatic testing for Islet- cell antibodies (ICA) or other autoantibodies (antibodies to glutamic acid dehydrogenase [ant-GAD] and anti-insulin) in serum may be helpful if establishing the diagnosis is important: a positive result is indicative of type $1 \mathrm{~A}$ diabetes. However, some patients have no evidence of autoimmunity and have no other cause for beta cell destruction (idiopathic type 1B diabetes mellitus ${ }^{[2]}$

Type 2 diabetes is responsible for over $80 \%$ of cases of diabetes in the United states, Canada, and Europe. Type 1 diabetes accounts for another 5 to $10 \%$, with the remainder due to other causes. New information has led to increased understanding of genetic defects related to diabetes, and the formerly termed MODY syndrome (maturity onset diabetes of the young) have now been linked to specific genetic defects ${ }^{[3]}$.

Cinnamon has been known from remote antiquite, and it was so highly prized among ancient nation that it was regarded as a gift for monarchs and other great potentates. It was imported to Egypt from China as early as $2000 \mathrm{BC}{ }^{[4]}$. In the middle Ages, the source of cinnamon was a mystery to the Western world Arab traders brought the spice via overland trade route to Alexandria in Egypt, where it was bought by Venetian traders from Italy who held a monopoly on the spice trade in Europe ${ }^{[5]}$. 
Table 1: Criteria for diagnosis of diabetes mellitus

\begin{tabular}{|c|c|}
\hline 1. & $\begin{array}{c}\text { 1-Symptoms of diabetes and a casual plasma glucose } 200 \\
\mathrm{mg} / \mathrm{dl}(11.1 \mathrm{mmol} / \mathrm{l}) \text {. casual is defined as any time of day } \\
\text { without regard to time since last meal. The classical symptoms } \\
\text { of diabetes mellitus include polyuria, polydipsia, and } \\
\text { unexplained weight loss. }\end{array}$ \\
\hline 2. & $\begin{array}{c}2-\mathrm{FPG} 126 \mathrm{mg} / \mathrm{dl}(7.0 \mathrm{mmol} / \mathrm{l}) \text {. Fasting is defined as no caloric } \\
\text { intake for at least } 8 \text { hours. }\end{array}$ \\
\hline 3. & $\begin{array}{c}3-2 \text { hrs. plasma glucose } 200 \mathrm{mg} / \mathrm{dl}(11.1 \mathrm{mmol} / \mathrm{l}) \text { during an oral } \\
\text { glucose tolerance test. The test should be performed as } \\
\text { described by WHO using glucose load containing the } \\
\text { equivalent of } 75 \mathrm{~g} \text { anhydrose glucose dissolved in water. }\end{array}$ \\
\hline
\end{tabular}

Its flavor is due to an aromatic essential oil which makes up 0.5 to $1 \%$ of its composition. This oil is prepared by roughly pounding the bark, macerating it in the sea - water, and then quickly distilling the whole ${ }^{[6]}$. It is of a golden yellowish color with characteristic odors of cinnamon and a very hot aromatic taste. The pungent taste and scent come from cinnamic aldehyde or cinnamaldehyde and by the absorption of oxygen as it ages, it darkens color and develops resinous compounds. Chemical composition of essential oil includes ethyl cinnamate, eugenol, cinnamaldehyde, betacaryophyyllene, linalool and methyl chavicol ${ }^{[7]}$. Cinnamon leaf oil has a warm, spicy, but rather harsh odors, lacking the rich body of the bark oil ${ }^{[8]}$. Its major constituents are eugenol rather than cinnamaldehyde, Its used as flavoring agents for seasoning and savory snacks. As a cheap fragrance it is added to soaps. The oils high eugenol content also makes it valuable as source of this chemical subsequent conversion into iso-eugenol. another flavoring agents.

Glucose is the most abundant monosaccharide, a subcategory of carbohydrates. The naturally occurring form of glucose is d-glucose, while l-glucose is produced synthetically in comparatively small amounts and is of lesser importance. Glucose is a monosaccharide containing six carbon atoms and an aldehyde group and is therefore referred to as an aldohexose. $\left(\mathrm{C}_{6} \mathrm{H}_{12} \mathrm{O}_{6}\right)^{[9]}$.

Streptozotocin (STZ, 2- deoxy-2- (3 methyl 3nitrosoureido) D - glucopyranose) is synthesized by streptomycetes achromogenes and is used to induce both insulin dependent and non - insulin dependent diabetes mellitus (IDDM and NIDDM respectively). The frequently used single intravenous dose in rat to induce IDDM is between $40-60 \mathrm{mg} / \mathrm{kg} \mathrm{b.w}{ }^{[10]}$, but higher dose are also used

\section{Materials and methods \\ Preparation of plant extract}

Dried cinnamon park was obtained from the local market, crushed by using electrical crusher to obtain the powder. The solvent extraction was performed by using petroleum ether, chloroform, ethyl acetate, ethanol and distilled water to get the aqueous extract of the plant. This was done by using continuous percolation process and the method used for this, was Soxhlet apparatus extraction ${ }^{[11]}$.

500 grams of coarse plant powder were put in the thimble siphons of Soxhlet after maceration in the same solvent for 15 minute, the flask of Soxhlet was filled with about one liter of the used solvent and heating of solvent was started at temperature $60-80{ }^{\circ} \mathrm{C}$.

And by condensation process the solvent in the thimble siphons off into main vessel containing the extract. The process continued for 4-5 times until complete extraction was achieved. The solvent from the flask was evaporated by using the rotatory evaporator under vacuum at temperature of $40-50{ }^{\circ} \mathrm{C}$ and rotation was continued until the extract of specific solvent was obtained

The extraction process started by using solvent with less polarity and gradually increasing the polarity with other solvents as follow

Petroleum ether, chloroform, ethyl acetate, ethanol and water. Finally, 20 grams of dry powder were obtained from each complete extraction cycle, the percent of yield was $4 \%$

\section{Effect of cinnamon extract on acute hyperglycemia induced by $D$ - glucose}

Male albino mice were used, animals were divided into seven groups each of six animals. The first group was control group it was treated with normal saline $(0.2$ $\mathrm{ml} /$ mouse I.P). The second group was given a single dose of $\mathrm{D}$ - glucose $(10 \mathrm{~g} / \mathrm{kg}, \mathrm{IP})$ it was the positive control group ${ }^{[12]}$. The third, fourth, fifth, sixth and seventh groups were treated with single dose of cinnamon extract $(300 \mathrm{mg} / \mathrm{kg}$ PO) at same time. Later on, these five groups were injected by D - glucose (10 g/kg IP) ad different time intervals from the treatment with cinnamon extract at 1, 3, 6, 10, $24 \mathrm{hrs}$.). The blood glucose level was estimated in all animal groups by using Accu- cheek glucose test strip this was by piercing the tail of the mice, a drop of blood was placed on a blood glucose test strip which then inserted into glucose meter.

\section{Estimation of the effect of cinnamon extract on chronic hyperglycemia induced by streptozotocin}

To induce diabetes female mice were injected with streptozotocin $(100 \mathrm{mg} / \mathrm{kg} \mathrm{IP})$ streptozotocin was dissolved in $0.1 \mathrm{~mol} / \mathrm{L}$ sodium citrate buffer $(\mathrm{pH} 4.0)$ and injected within 5 minute ${ }^{[13]}$. To determine the effects of cinnamon extract mice were divided into five groups each of six animals the first non-treated control group was given a citrate buffer $(0.5 \mathrm{ml} /$ mouse $\mathrm{PO})$ and the third group was treated only with cinnamon extract $(300 \mathrm{mg} / \mathrm{kg}$ PO) for 2 weeks (positive control group). The second, fourth and fifth animal group were fasted about 12 hours prior treatment with single dose of streptozotocin (100 mg/kg IP).

The fourth group was pretreated with cinnamon extract $(300 \mathrm{mg} / \mathrm{kg} /$ day PO) for two weeks prior to treatment with streptozotocin and lastly the fifth group treated with a single dose of glibenclamide $(0.5 \mathrm{mg} / \mathrm{kg} \text { PO })^{[14]} .2$ hours before collecting blood on the day of sacrifice mice were kept overnight fasted then decapitated without anesthesia and trunk blood was collected into perhilled tubes containing 1 $\mathrm{mg} / \mathrm{ml}$ of EDTA for insulin and glucose determination. Blood glucose was determined using glucose oxidase kit, plasma insulin was assayed using a standard radioimmunoassay technique.

Statistical Analysis: The result of this experiment was done by use of descriptive analysis as the mean S.E.M. Data was analyzed by using $\mathrm{T}$ - test in some experiment and the method of analysis of variance (ANOVA). The significant of analysis is indicated by the $p$ value if it is equal to less than 0.05 it is considered as statistically significant.

\section{Results \\ Hypoglycemic effect of cinnamon extract on D- glucose induced hyperglycemia}

As shown in figure (1), the plasma glucose level at different time intervals from the administered single Cinnamon 
extract dose was significantly decreased after 6 hours as compared to thee all other groups (control, zero time, at 1 hour, at 3 hour, at 10 hour and at 24 hours) and the $p$ value was $(p<0.001)$.

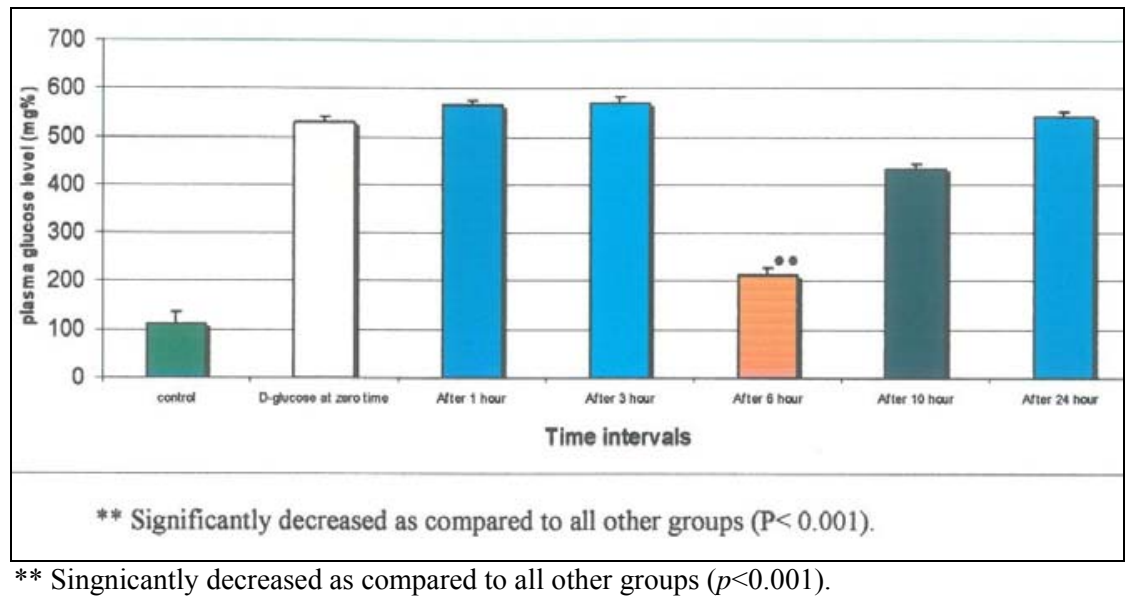

Fig 1: Effect of CE on acute hyperglycemiainduced by D- Gluoose Administered at Different time intervals

The effect of cinnamon extract on streptozotocin induced hyperglycemia

As shown in figure (2) by using ANOVA followed by post Hoc test, our data indicated that, there was a significant increase in the level of glucose in the streptozotocin treated groups as compared to all other groups. $(p<0.001)$.

On other hand the pretreated cinnamon extract group showed a significant decrease in the glucose level as compared to the streptozotocin group ( $\mathrm{p}, 0.001$ ), also the glibenclamide significantly reduced the glucose level as compared to the streptozotocin group $(p<0.005)$.

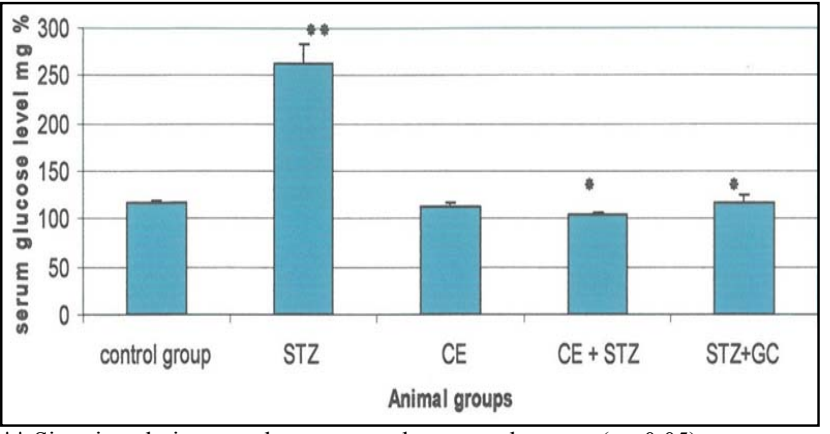

** Singnicantly increased as compared to control groups $(\mathrm{p}<0.05)$.

* Singnicantly decreased as compared to STZ groups $(\mathrm{p}<0.001)$.

Fig 2: Effect of CE and Glibanclamide (GC) hyperglycemia induced by A single dose of STZ in Mice.

Discussion: Cinnamon has been widely used as spice and flavoring agent, some previous studies have been shown that it may be clinically useful in treatment of certain diseases such as type 2 diabetes mellitus, dyspepsia, anorexia, inflammatory disorders in addition to its antimicrobial activity ${ }^{[15]}$.

The effect of cinnamon extract on hyperglycemia was investigated using 2 animal models namely D -glucose model) and chronic streptozotocin model. Previous studies suggested that $\mathrm{D}$ - glucose is mediated by the stimulation of the lateral part of the dorsal parabrachial nucleus (LPBD) enhancing glucagon release and suppression insulin secretion leading to hyperglycemia. D - glucose affects the suprachiasmatic nucleus $(\mathrm{SCN})$ and $\beta$-adrenergic mechanisms that are involved in the hyperglycemic response to (LPBD) stimulation ${ }^{[16]}$.

Pretreatment with oral cinnamon extract had a weak and delayed hypoglycemic effect which was significant 6 hour after treatment. This transient and delayed effect indicated that the cinnamon extract is slowly absorbed and therefore it may have low bioavailability. In addition the hypoglycemic effect which occurred only after 6 hour may be explained through an extra pancreatic mechanism, this may imply that cinnamon extract may affect (LPBD or SCN) nuclei in hypothalamus and therefore counteracting the effect of D glucose by suppressing glucagon and enhancing insulin secretion. More over methyl hydroxyl chalone (MHCP) one of the component of cinnamon extract was demonstrated in vivo to activate glycogen synthase and inhibit glycogen synthase kinase $3 \mathrm{~B}^{[17]}$.

Streptozotocin may be given in multiple low doses for induction of IDDM in mouse such effect is mediated by activation of immune function. However ${ }^{[18]}$ demonstrated that the nonspecific activation of immune system via complete Freud's adjuvant prior to streptozotocin injection allows to reduce its diabetogenic dose even in the rat.

NIDDM can be easily induced in rats by intravenous or intraperitoneal treatment with $100 \mathrm{mg} / \mathrm{kg} \mathrm{b.w}$.

Streptozotocin action in the B cell is accompanied by characteristic alteration in blood insulin and glucose concentration. Two hours after injection, the hyperglycemia is observed with a concomitant drop in blood insulin, about six hours later hypoglycemia occurs with high levels of blood insulin. Finally, hyperglycemia develops and blood insulin levels decrease. These changes in blood glucose and insulin concentrations reflects abnormalities in B cell function.

A study was carried out in Jordan on 75 patients with type 2 diabetes for 4 weeks; the patients were asked to take $2 \mathrm{~g}$ of ground cinnamon (two 500 milligrams of cinnamon capsules) immediately after breakfast, lunch, and dinner; and, as a result, a daily dose of $6 \mathrm{~g}$ of cinnamon was found to be effective in reducing blood glucose in a short time ${ }^{[19]}$. In a parallel study on patients with type 2 diabetes after menopause, the patients were given cinnamon (Cinnamomum cassia, $1.5 \mathrm{~g} /$ day) and placebo supplements for 6 weeks. Based on the study, no change was detected in 
preprandial blood glucose, preprandial insulin and HbA1c levels, blood lipids, and whole-body insulin resistance/sensitivity ${ }^{[20]}$. An another study, 25 postmenopausal women were examined. The consumption of $1500 \mathrm{mg}$ of cinnamon per day has been observed not to reduce blood sugar compared to placebo ${ }^{[21]}$.

CIN effects were investigated on fasting blood glucose, insulin, oral glucose tolerance test (OGTT), insulin tolerance test (ITT), liver biomarkers, lipid profile, oxidative stress biomarkers, serum advanced glycation end products (AGEs) and its receptors (RAGE) in the aorta, and histopathology of the liver and aorta. Additionally, the mRNA expression of hepatic insulin signaling pathway genes, phosphorylated AKT (serine 473) (P-AKT ser ${ }^{473}$ ) level, and aortic nitric oxide synthase 3 (eNOS) and NADPH oxidase4 (NOX4) were determined. CIN treatment for 30 days significantly decreased OGTT, ITT, fasting blood glucose, insulin, and HOMA-IR and increased HOMA- $\beta$ index when compared to diabetic rats. $\mathrm{CIN}$ also improved lipid profile and decreased serum alanine aminotransferase (ALT) and aspartate aminotransferase (AST) activity, serum AGEs, and aortic RAGE. Additionally, CIN treatment significantly decreased hepatic malondialdehyde (MDA), increased hepatic and aortic glutathione (GSH) and superoxide dismutase (SOD), and decreased steatosis and inflammation observed in liver tissue of rats. Additionally, significant elevation in mRNA expression of insulin receptor substrate1 (IRS1), phosphatidylinositol 3-kinase regulatory subunit1 (PI3K-P85 subunit), and AKT serine/threonine kinase2 (AKT2); increased levels of PAKT ser $^{473}$ and aortic eNOS; and decrease in mRNA expression of NOX4 were detected in CIN-treated group when compared to diabetic group. This study suggests antidiabetic and antioxidant effects of CIN probably through upregulation of eNOS and IRS1/PI3K/AKT2 signaling pathway and alleviating AGEs, RAGE, and NOX4 elevation [22].

\section{References}

1. Genuth S, Albert KG, Bennett P. Follow up report on the diagnosis of diabetes mellitus. Diabetes Care 2003;26:3160.

2. Librman IM, Pietropaolo M, Trucco M. Islet cell autoimmune in white and black children and adolescents with IDDM. Diabetes Care 1998;21;1824.

3. Rother KI. Diabetes treatment - Bridging the divide N Engl J Med 2007;356(15):1499-1501.

4. Jayaprakasha GK, Jagan Mohan Rao L, Sakariah KK. Volatile constituents from cinnamon zeykanicum fruit stalks and their antioxidant activities. J Agric Food Chem 2003;51(15):4344-4348.

5. Gruenwald J. PDR for Herbal Medicine $3^{\text {rd }}$ ed, Montvale NJ Thompson PDR; 199- 200.arvil- Tylor, K.J Anderson R.A, and Graves, D.J (2001). A hydroxychalcone deived fron cinnamon function as amemetic for insulin in 3T3-L1 adipocytes. J. Am. Coll. Nutr 2004;20:327-336.

6. Moestafa A, Badeges F. Distillation of cassia leaf oils (Cinnamon burmanii, C, Zeylanicum and C.cassia) by cohobation method and identification of oil components. Warta Industri Hadil Pertanian Indonesia 1986;3(1):22-25.

7. Arpi A, Anahit M, Margarit P, Naira S, Anush B, et al. Chemical composition and some biological activities of the essential oils from basil Ocimum different cultivars BMC Complementary and Alternative Medicine 2017, v.17; PMC5248495.

8. Lockwood GB. Major constituents of the essential oils of Cinnamon cassia Blume growing in Nigeria. Planta Medica 1979;36(4):380-381.

9. Purseglove JW, Brown EG, Green CL, Robbins SRJ. Cinnamon and cassia ; pp 100-173. In spices, Volume 1, 439. London: Longman 1981.

10. Ganda OP, Rossi AA, Like AA. Studies on streptozotocin diabetes. Diabetes 1976;25:595-603.

11. Trease and Evans pharmacology. Comparison of Phytochemicals and Anti-Nutritional Factors in Some Selected Wild and Edible Bean in Nigeria. Food and Nutrition Sciences, (7) 11 $1^{\mathrm{TH}}$. ED 1978.

12. El-Debani AH, El-Darrat A, Abdellatif AG. Reversal of drug induced hyperalgesia by transient hyperglycemis. Proceedinh of the third Jamahiriya Conference of Medical Sciences. Tripol1, 31 st May $3{ }^{\text {rd June } 1996 .}$

13. Beom K, Eun-Kyung K, Eun-Sil J, Do-Go R. Cortex cinnamon extract prevents streptozotocin- and cytokine - induced B- cell damage by inhibiting NF-Kb. World J Gatroenterol 2006;12(27):4331-4337.

14. Jean-Jacques D, Dugald S, Dan P, Kieran C, Taryan F, Edward M, et al. From type 2 diabetes to antioxidant activity: A common and cassia cinnamon bark Can.J Physiol. Pharmacol 2007;85:837-847.

15. Fujiwara K, Nagai S, Takagi S, Nakagawa $H$. Hyperglycemia induced by electrical stimulation of lateral part of the dorsal parabrachail nucleus Am J Physiol Endocrinol Metab 1988;254:E468-E475.

16. Jarvil-Tylor KJ, Anderson RA, Graves DJ. A hydroxychalone derived from cinnamon function as amimetic for insulin in 3T3-L1 adipocytes.J. Am. Coll. Nutr 2001;20:327-336.

17. Ziegler M, Zeigler B, Hehmke B. Sever hyperglycemia caused by autoimmunization to $\mathrm{B}$ - cells in rats Diabetologia 1984;27:163-165.

18. Portha B, Levacher C, Picon L, Rosselin G. Diabetogrnic effet of streptozotocin in the rat during the perinatal period. Diabetes 1974;23:889-895.

19. Al Jamal AR, Effects of cinnamon on blood glucose and lipids levels in diabetic patients (type1), African Journal of Biochemistry Research 2009;3:181-184. View at: Google Scholar

20. Rudkowska. Functional foods for health: focus on diabetes Maturitas 2009;62(3):263-269. View at: Publisher Site | Google Scholar

21. Vanschoonbeek K, Thomassen BJW, Senden JM Wodzig, LJC Van Loon. Cinnamon supplementation does not improve glycemic control in postmenopausal type 2 diabetes patients, Journal of Nutrition 2006;136(4):977-980. View at: Publisher Site | Google Scholar

22. Marwa EA, George S, Rami AA, Ghada MS, Hatem A Salem. Cinnamaldehyde ameliorates STZ-induced rat diabetes through modulation of IRS1/PI3K/AKT2 pathway and AGEs/RAGE interaction NaunynSchmiedeberg's Archives of Pharmacology 2019;392:243-258. 